\title{
DIVERSIDADE SEXUAL E INTEGRAÇÃO LINGUÍSTICA: FACILITANDO O CONTATO INICIAL DE MIGRANTES COM OS TRANSGÊNEROS BRASILEIROS
}

\author{
DIVERSIDAD SEXUAL E INTEGRACIÓN DEL IDIOMA: FACILITAR EL \\ CONTACTO INICIAL DE LOS MIGRANTES CON LAS TRANSGENERÍAS \\ BRASILEÑAS
}

\author{
SEXUAL DIVERSITY AND LANGUAGE INTEGRATION: FACILITATING \\ INITIAL CONTACT OF MIGRANTS WITH BRAZILIAN TRANSGENERIES
}

João Roberto dos Reis de SOUZA ${ }^{1}$

RESUMO: Este artigo aborda o tema de diversidade de gênero na perspectiva da integração linguística no contexto de migração e sua relevância se dá devido a marginalização dos transgêneros causadas também pelo indevido tratamento. Portanto, o artigo tem como objetivo principal averiguar como tem sido tratados os transgêneros no Brasil, através de textos acadêmicos, jornalísticos e cartilhas instrutivas, para que, quando cabível, sejam feitas as devidas sugestões de como devem ser tratados, contudo, sem desconsiderar toda a bagagem de conhecimentos acerca do tema pelos migrantes.

PALAVRAS-CHAVE: Transgênero(s). Transexualismo. Gênero e linguagem. Linguística de corpus.

RESUMEN: Este artículo aborda el tema de la diversidad de género en la perspectiva de la integración lingüística en el contexto de la migración y su relevancia se debe a la marginación de las personas transgénero también causada por un tratamiento indebido. Por lo tanto, el objetivo principal de este artículo es investigar cómo se ha tratado a las personas transgénero en Brasil a través de textos académicos, textos periodísticos y folletos de instrucción, de modo que, cuando sea apropiado, se hagan sugerencias apropiadas sobre cómo deben ser tratados, sin dejar de lado todo conocimiento del tema por parte de los migrantes.

PALABRAS CLAVE: Transgénero (s). Transexualismo. Género y lenguaje. Lingüística del cuerpo.

ABSTRACT: This article approaches the theme of gender diversity in the perspective of linguistic integration in the context of migration and its relevance is due to the marginalization of transgender people also caused by undue treatment. Therefore, the main objective of this article is to investigate how transgenders have been treated in Brazil through academic texts, journalistic texts and instructional booklets, so that, when appropriate,

${ }^{1}$ Universidade de Brasília (UnB), Brasília - DF - Brasil. Graduando em Ciências Sociais com habilitação em Sociologia. ORCID: https://orcid.org/0000-0001-5444-7877. E-mail: joaoroberto.pol@gmail.com 
appropriate suggestions are made as to how they should be treated, however, without disregarding all knowledge of the subject by migrants.

KEYWORDS: Transgender (s). Transsexualism. Gender and language. Corpus Linguistics.

\section{Introdução}

O transexualismo ainda é considerado uma patologia pela Organização Mundial de Saúde (OMS), um transtorno da identidade sexual classificado pelo CID-10 F64, embora recentemente tenha sugerido para a próxima versão a retirada da transexualidade da lista de doenças mentais. Segundo relatório da ONG internacional Transgender Europe (BALZER; HUTTA, 2012), o Brasil é o país onde mais ocorrem assassinatos de travestis e transexuais em todo o mundo. Entre outubro de 2016 e setembro de 2017, foram relatados 171 assassinatos de pessoas trans e gênero-diversas no Brasil, que correspondem a $41 \%$ dessas mortes no mundo, o que o torna o país que mais mata a população trans em números absolutos no universo alcançado pelo monitoramento. Isso é prova cabal de que esse grupo é severamente segregado em nossa sociedade, além do fato de que seus direitos mais básicos lhes são constantemente negados - tais como estudar, trabalhar, ser reconhecido e tratado de acordo com sua identidade de gênero, ter documentos que reflitam quem são, ou mesmo ir ao banheiro sem sentir-se discriminados.

Ultimamente, a comunidade transgênero tem se posicionado e se manifestado de forma mais veemente sobre algumas pautas sócio-políticas, como, por exemplo, a pressão pela aprovação e sanção do Decreto 8.727/16, que versa sobre os direitos dos transgêneros a usarem um nome social. Ademais, no dia 30 de março comemora-se o Dia Internacional da Visibilidade Trans, ocasião em que essa comunidade se organiza para fazer uma grande manifestação de conscientização da sociedade.

Ainda assim, as iniciativas tomadas até o momento não foram suficientes para oferecer uma melhoria significativa no que diz respeito ao reconhecimento e tratamento adequado dos membros dessa comunidade em nosso país: ora ficam marginalizados, ora são absolutamente invisíveis aos olhos da sociedade e do Estado. Quando os transgêneros socializam-se com pessoas cisgênero ${ }^{2}$, seja em órgãos públicos ou em seus próprios círculos de convivência pessoal, o despreparo fica evidente - muitas vezes elas não têm qualquer informação sobre

${ }^{2}$ Cisgênero é um termo usado para se referir às pessoas cujo se identificam com o gênero que foi designado em seu nascimento. Por exemplo: uma mulher cisgênero é aquela pessoa que foi designada com o gênero feminino ao nascer e se identifica com ele. 
como se referirem ou se dirigirem a um transgênero, quando não optam por ignorar essas convenções.

Para além dos problemas advindos de tabus, do machismo, de convicções religiosas preconceituosas, ou mesmo da falta de civilidade de alguns, há muitos casos em que a desinformação parece ser o principal fator a impedir uma melhor integração desse grupo na sociedade. E um primeiro passo para essa integração passa, a nosso ver, por uma ação instrutiva de cunho linguístico, que parta de um estudo sobre as terminologias e maneiras mais adequadas de tratamento para as pessoas transgênero. Com isso, visamos a conscientização da população brasileira em geral e, no caso específico desta pesquisa, dos refugiados e demais migrantes da região do DF (como, por exemplo, os alunos estrangeiros da Universidade de Brasília).

O foco nessa população se dá por dois motivos: primeiramente, porque também são um grupo de pessoas que, especialmente no caso dos refugiados, já vêm de uma situação de marginalização e/ou de ameaça a seus direitos humanos, o que os torna vulneráveis e dificulta sua integração social e cultural - ainda mais quando esses migrantes são transgênero ou da comunidade LGBTQIA+ (Lésbicas ${ }^{3}$, Gays $^{4}$, Bissexuais ${ }^{5}$, Transgêneros ${ }^{6}$, Travestis $^{7}$, Queer ${ }^{8}$, Intersexo ${ }^{9}$, Assexual $^{10}$ ). Por outro lado, é possível que alguns migrantes venham de culturas ainda mais repressoras e preconceituosas que a brasileira, em que informações sobre a transexualidade sejam ainda mais escassas. Seja qual for o caso, o próprio fato de a maioria

\footnotetext{
${ }^{3}$ Mulheres que se sentem atraídas por pessoas do mesmo sexo, ou seja, mulheres, o que não se relaciona com sua identidade de gênero. Pessoa que se atrai afetivo-sexualmente por pessoas de gênero igual àquele com o qual se identifica.

${ }^{4}$ Homens que se sentem atraídos por pessoas do mesmo sexo, ou seja, homens, o que não se relaciona com sua identidade de gênero. Pessoa que se atrai afetivo-sexualmente por pessoas de gênero igual àquele com o qual se identifica.

${ }^{5}$ Pessoa que se atrai afetivo-sexualmente por pessoas de qualquer gênero

${ }^{6}$ Conceito "guarda-chuva" que abrange o grupo diversificado de pessoas que não se identificam, em graus diferentes, com comportamentos e/ou papéis esperados do gênero que lhes foi determinado quando de seu nascimento.

${ }^{7}$ Entende-se, nesta perspectiva, que são travestis as pessoas que vivenciam papéis de gênero feminino, mas não se reconhecem como homens ou como mulheres, mas como membros de um terceiro gênero ou de um nãogênero.

${ }^{8}$ É uma teoria gênero que afirma que a orientação sexual, a identidade sexual e de gênero dos indivíduos são o resultado de um constructo social e que, portanto, não existem papéis sexuais essencial ou biologicamente inscritos na natureza humana.

${ }^{9}$ Pessoa cujo corpo varia do padrão de masculino ou feminino culturalmente estabelecido, no que se refere a configurações dos cromossomos, localização dos órgãos genitais (testículos que não desceram, pênis demasiado pequeno ou clitóris muito grande, final da uretra deslocado da ponta do pênis, vagina ausente), coexistência de tecidos testiculares e de ovários. A intersexualidade se refere a um conjunto amplo de variações dos corpos tidos como masculinos e femininos, que engloba, conforme a denominação médica, hermafroditas verdadeiros e pseudo-hermafroditas.

${ }^{10}$ Pessoa que não sente atração sexual por pessoas de qualquer gênero.
} 
não ser falante nativa da língua portuguesa impõe uma barreira linguística e cultural que, esperamos, poder contribuir para superarem com nossa pesquisa.

Nesse sentido, nosso trabalho se insere no âmbito do Projeto MOBILANG ${ }^{11}$ Migrações e Fronteiras no Distrito Federal, coordenado pelas Profas. Sabine Gorovitz e Susana Martínez, da Universidade de Brasília, que tem por objetivo principal a integração social da população imigrante acolhida pelo Distrito Federal por meio do oferecimento de apoio linguístico aos refugiados, como forma de garantir seus direitos humanos. Essa integração social é realizada em conexão com diferentes instituições (CONARE - Comitê Nacional para os Refugiados, DPU - Defensoria Pública da União, Polícia Federal, Ministério das Relações Exteriores, postos de saúde, penitenciárias, centros de detenção, ACNUR - Alto Comissariado das Nações Unidas para os Refugiados, IMDH - Instituto de Migrações e Direitos Humanos, etc.).

Nosso plano foi, após fazer uma revisão bibliográfica sobre o transexualismo, considerando-o da perspectiva dos Estudos de Gênero e da Sociolinguística, lançar mão da Linguística de Corpus para compilar um corpus de textos e materiais informativos autênticos, produzidos em língua portuguesa, sobre as principais temáticas da cultura trans no Brasil. Este corpus serviu de base para um levantamento inicial das terminologias, definições e expressões de tratamento mais utilizadas e preferidas pela comunidade trans. Os dados servirão de ponto de partida para a organização de um material de divulgação, a ser distribuído em meio impresso e/ou eletrônico para todos os órgãos envolvidos no acolhimento de refugiados e demais migrantes no Distrito Federal e região.

No que se segue, apresentamos as noções teóricas básicas que fundamentam nosso projeto de pesquisa para, na sequência, descrever a metodologia empregada na coleta, preparo e análise do corpus de pesquisa. Por fim, apresentamos e discutimos os resultados obtidos, fazendo algumas considerações sobre as dificuldades encontradas e os próximos passos que esperamos dar para a continuação da pesquisa.

\section{Fundamentação teórica}

Diante da necessidade de promover o entendimento mais adequado da diversidade da identidade de gênero e o seu devido tratamento sugerindo o tratamento adequado a estas pessoas para que não se perpetue a marginalização desse grupo, portanto foi usado três fundamentações teórico-metodológica na pesquisa.

${ }^{11}$ Disponível em: http://projetomobilang.wixsite.com/home. Acesso em: abr. 2017. 
Primeiramente, embasamos a pesquisa com o estudo de gênero que é a área da ciências humanas que estuda as Relações de Gênero, as definições dos gêneros considerando suas respectivas diversidades e articulação das noções sociais de gênero, práticas e expressões corporais e sexuais. Esta pesquisa também perpassa pelo entendimento de que existem novas identidades de gênero que atravessam o binarismo homem-mulher representados pelo quadro conceitual de gênero no Brasil (KULICK, 2008). O que foi fundamental para entender as relações de gênero no Brasil e mais especificamente a travestilidade e sua relação com a sociedade brasileira.

Outra abordagem teórica que usamos foi a Sociolinguística a é área da linguística que realiza o seu estudo na perspectiva na variação e mudança dentro da língua, ou seja, de fenômenos linguísticos. Portanto, nesta pesquisa, a coleta conta com textos, resultando em um total de palavras analisados sob a perspectiva da Sociolinguística (CALVET, 2002) e, por isso, não se restringe aos aspectos estruturais da língua: entende-se que a diversidade de itens lexicais para a comunidade é consequência justamente da produção de variantes. Dessa forma a Sociolinguística nos serviu para análise dos itens lexicais se estes, por exemplo, variam ou não.

Além disso, embasamo-nos na Linguística de Corpus propostos por Berber Sardinha (2004) e de Terminologia associada a Linguística de Corpus de Teixeira (2008) que é uma área da linguística que versa sobre análise de dados do textos por meio da coleta deles. Dessa forma, a linguística de corpus foi indispensável para esta pesquisa que nos serviu para coletar textos referentes e direcionados para pessoas trans e analisar como esse grupo tem sido tratado, sobre tudo ver o que se tem usado, de fato, ao se referir à estas pessoas em relação direta ao que dizem que deveria ser usado. Ademais, a área pode ser aplicada de maneira interdisciplinar, ou seja, sem mudar a orientação teórica dos outros assuntos caso seja necessário.

\section{Metodologia}

Para saber se os transgêneros brasileiros de fato têm sido tratados adequadamente foi preciso coletar textos jornalísticos e materiais informativos a respeito da temática trans no Brasil por isso optamos pela abordagem de Berber Sardinha (2004) para a compilação do corpus e a Terminologia direcionada por corpus (TEIXEIRA, 2008).

O primeiro passo foi coletar os textos que são sobre pessoas trans e direcionados para este público em específico. Os textos foram todos extraídos exclusivamente pela internet. É 
considerável dizer que foi escolhido três tipos de textos para se ter uma visão bastante ampla de como se referem a este público. Por isso, foi escolhido textos jornalísticos, textos de blogs e cartilhas.

Após a coleta foi necessário transformar todos os arquivos em formato txt, no formato UTF-8 e, sobretudo, colocar seus respectivos cabeçalho com suas etiquetas para identificação. É necessário fazer a limpeza do arquivo removendo caracteres que não são possíveis de ler pelo programa AntConc.

Após a coleta e a com o auxílio do programa AntConc, realizou-se uma leitura vertical automática, ou seja, localizar os padrões de uso da palavra de forma a apresentar a reincidência de itens lexicais referentes à população trans brasileira. Além disso, foi possível explorar estatisticamente a ocorrência de determinadas palavras por meio do Rank, ou seja, por exemplo: a observação de quantas vezes ocorre a palavra "trans" dos corpus coletado. E ver as palavras combinatórias usadas para se referir a determinados objetos e/ou coisas.

Figura 1 - Leitura vertical automática

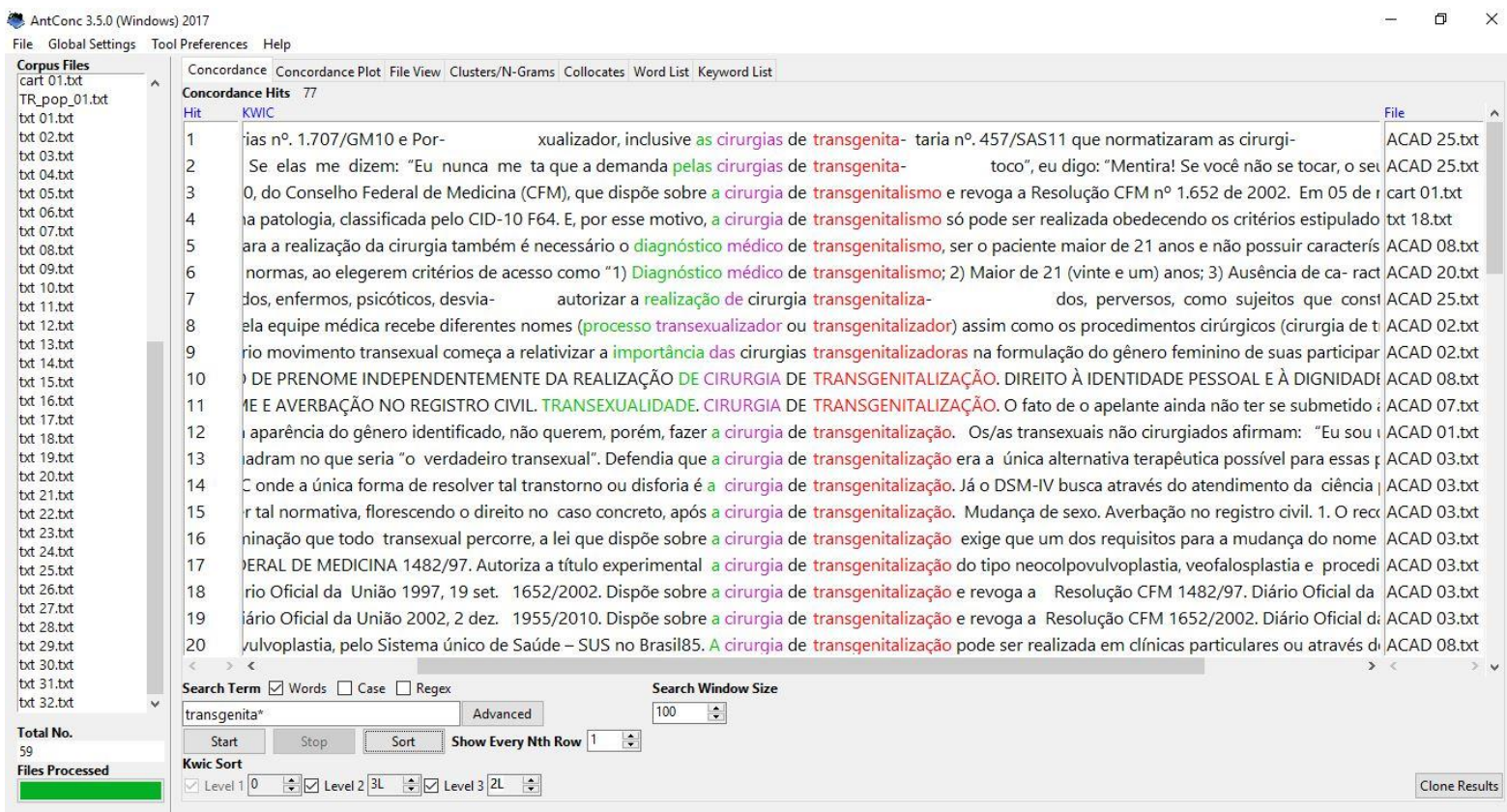

Fonte: elaboração própria

Para a análise após a coleta, optamos pela perspectiva da Sociolinguística em Calvet (2002): por exemplo, trata-se de variação diastrática o fenômeno da diversidade de palavras para se referir à comunidade transgênero, como parte ou não do grupo em questão. Os materiais de caráter instrutivo, a exemplo dos que compõem o repertório do gênero textual cartilha, formaram a base teórica das temáticas LGBTQIA+ e dos contextos de imigração e 
refúgio: são mostradas algumas alternativas linguísticas entre as mais adequadas na atualidade brasileira para se referir à comunidade trans, bem como é apresentada a realidade do estrangeiro no Brasil a partir do conteúdo.

A partir desse entendimento evidencia-se a função da pessoa transgênero especificamente enquanto sujeito ativo no processo de construção do sentido de variantes que podem se tornar ora prestigiadas, ora estigmatizadas.

\section{Análise de dados}

A ideia era produzir um material informativo, a ser distribuído para todos refugiados e demais migrantes de DF e região, contendo informações sociolinguísticas e culturais a respeito do transexualismo, mas devido à complexidade e tempo não seria possível fazer esse grande levantamento de forma adequada.

Para tanto, usando a abordagem teórico-metodológica da Linguística de Corpus (BERBER SARDINHA, 2004) e princípios básicos da Sociolinguística (CALVET, 2002), compilamos um corpus sobre as principais temáticas da cultura trans no Brasil, que serviu de base para um levantamento inicial, conforme relatamos a seguir.

O corpus coletado tem 182.444 palavras-ocorrência (tokens) e 18.308 palavras-forma (types). A primeira palavra de conteúdo é "gênero", na posição 20, pela ordem decrescente de recorrência, com 1.169 ocorrências no corpus, seguida de "pessoas" (30a , 668 oc.), “transexuais" (31 a , 574), "sexo" $\left(32^{\mathrm{a}}, 564\right)$ e "trans" $\left(35^{\mathrm{a}}, 502\right.$ oc. $)$. 
Figura 2 - Principais temáticas da cultura trans no Brasil

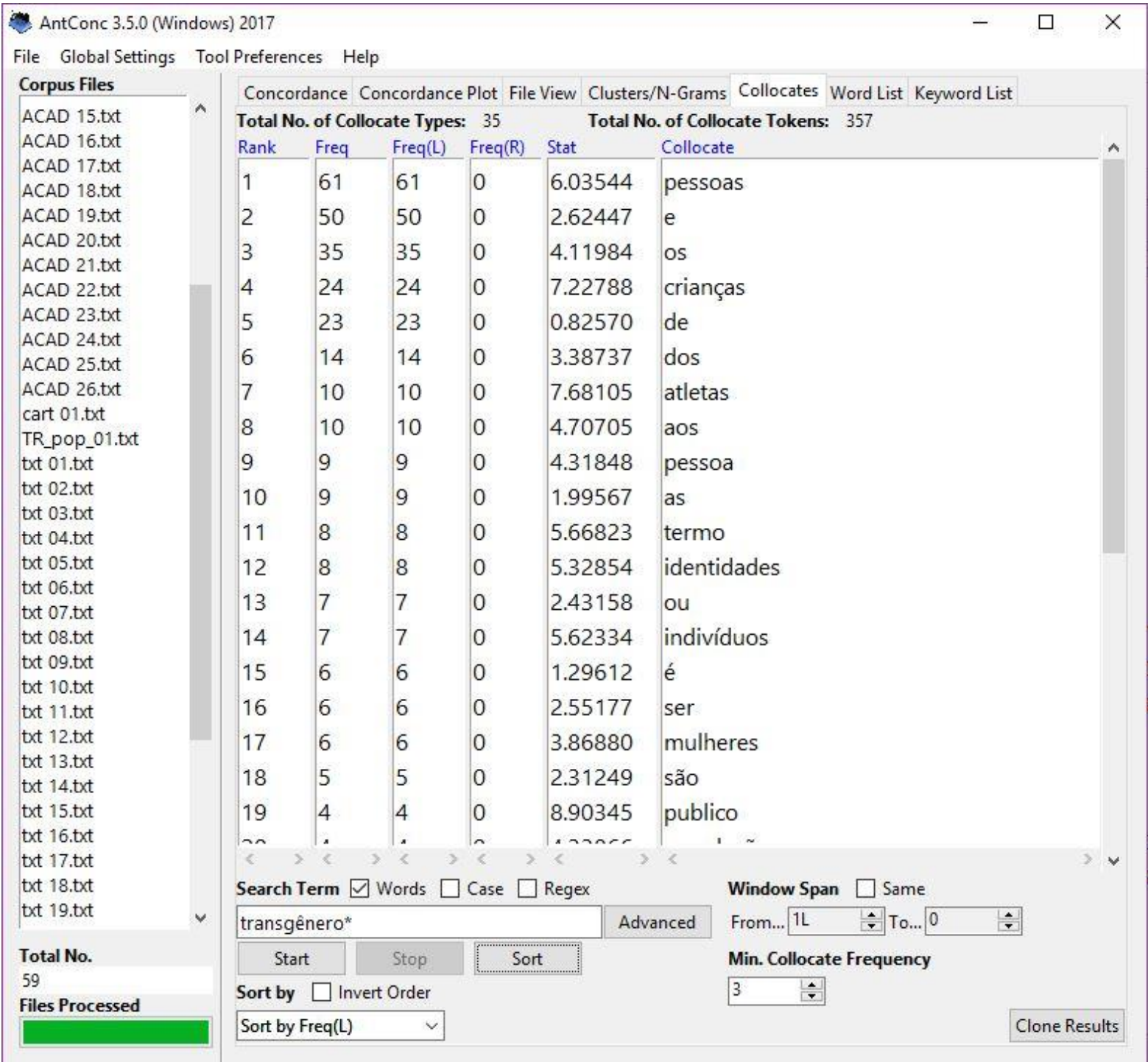

Fonte: elaboração própria

Pela dificuldade de se analisar cada segmento do grupo transgênero, fizemos aqui um recorte para aprofundar nossa análise focando o prefixo / vocábulo "trans(-)", que ocorre 2.896 vezes no corpus. Dentre as formas mais produtivas, identificamos o binômio "travestis e transexuais" (116 oc.); "pessoa(s) trans" (128 oc.); “transexual” (296 oc.); "transexualidade(s)" (144 oc.); "transexualismo" (75 oc.) e "transgênero(s)" (456 oc.). Chamou-nos a atenção a ocorrência de "transgênera(s)" (36 oc.), que co-ocorre com "pessoa(s)" 21 vezes. Já a forma masculina, com "transgênero" funcionando como adjetivo invariável, "pessoa(s) transgênero", ocorreu 70 vezes no corpus. O binômio "travestis e trans" foi muito menos produtivo que a forma contendo "transexuais", ocorrendo apenas 6 vezes. 
Figura 2 - Aprofundamento da análise

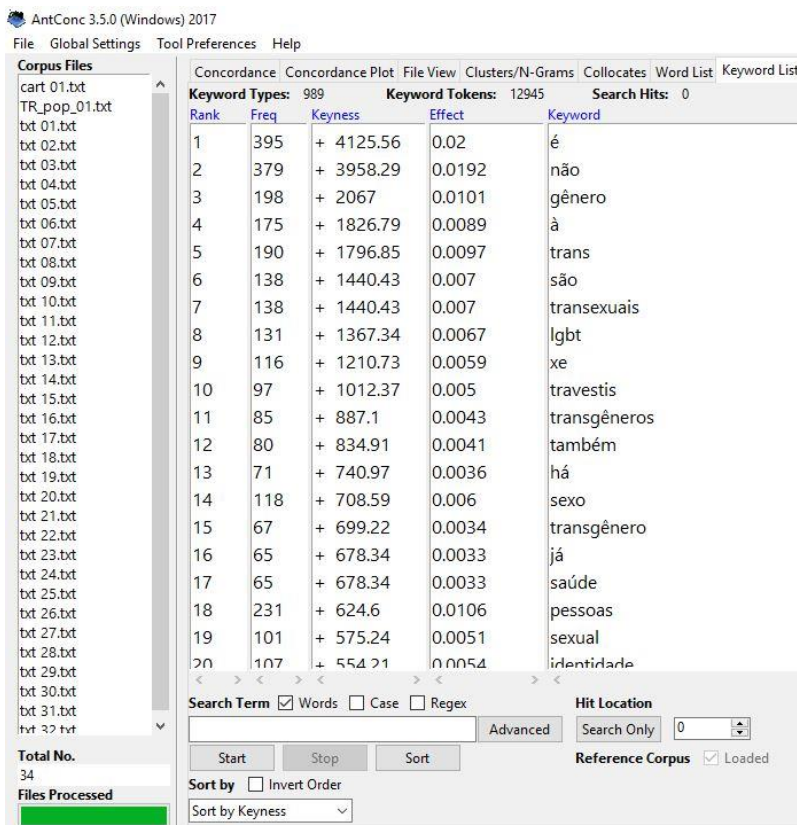

Fonte: elaboração própria

Ainda pela dificuldade de se analisar cada segmento do grupo transgênero e suas especificidades foi necessário fazer três recortes nesta pesquisa, sendo eles: homem transgênero, mulher transgênero e travestis. Foi observado o pronome de tratamento para cada um desses termos, dessa forma é possível constatar as seguintes ocorrências:

Para os homens transgêneros, o termo "'homem"' aparece 112 e "'homens"' 96 vezes e sempre relacionados ao artigo "'o". Portanto, para se referir aos homens transgêneros é recomendável referi-lo com o pronome "o", logo o homem transgênero ou transexual.

Para as mulheres transgêneros, o termo "'mulher" aparece 164 vezes e 'mulheres" aparece 180, tratadas sempre com o artigo 'a'". Portanto, para se referir às mulheres transgêneros é sugestivo referi-la com o pronome "a" logo, a mulher transgênero ou transexual.

Para as travestis, aparecem 369 palavras, tratadas majoritariamente com o artigo ' a' e apenas pouco se referenciam a travesti no artigo masculino, ' o', Portanto, o artigo adequado para se usar ao se referir a pessoa travesti é o "'a", logo é recomendável dizer: a travesti.

Além disso, é considerável pontuar que caso exista alguma dúvida de como tratar uma pessoa trans é indicado que pergunte a ela como prefere ser tratada. 


\section{Considerações finais}

Devido a marginalização sofrida pelos transgêneros foi necessário fazer uma pesquisa para que fosse sugerido o devido tratamento a estas pessoas. Para isso foi feita uma revisão bibliográfica sobre o transexualismo, revisão bibliográfica dos Estudos de Gênero relacionados diretamente com a transgeneridade e, além disso, da Sociolinguística, tomou-se por base principalmente a Linguística de Corpus com a função de compilar um corpus de textos acadêmicos, jornalísticos e materiais informativos.

Posteriormente, foi feita a coleta dos textos, passando-os para o formato txt e, com o auxílio do programa AntConc para ser feita a leitura vertical dos termos escolhidos para análise. Com base nesta leitura vertical foi possível constatar os pronomes de tratamento que vêm sendo utilizados para se referir a estas pessoas. Como por exemplo:

Figura 4 - Leitura vertical

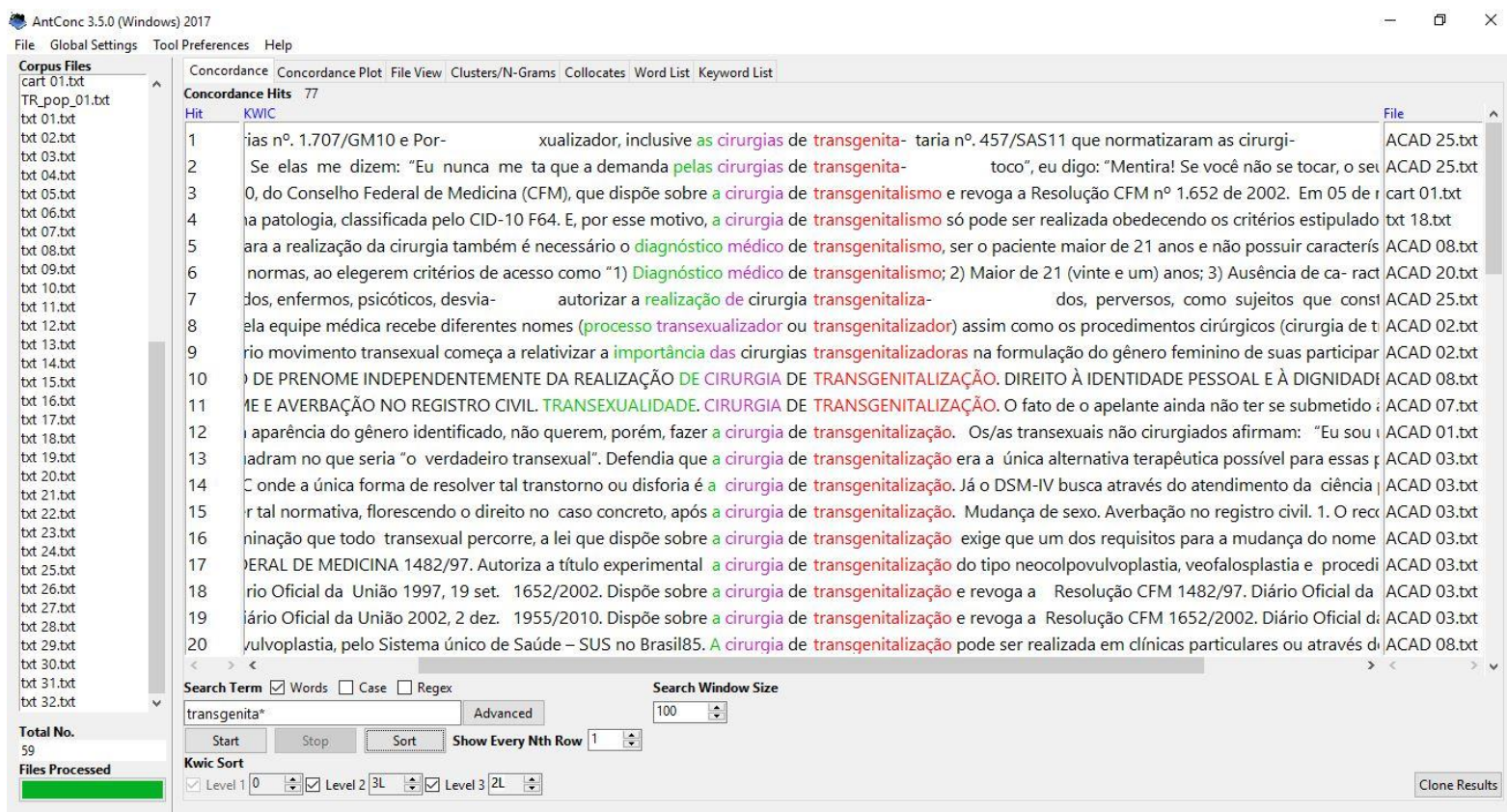

Fonte: elaboração própria

É esperado que, com esta pesquisa, tenha se dado mais um grande passo para o reconhecimento da comunidade transgênero brasileira pelos refugiados e demais migrantes, oferecendo aos órgãos competentes de acolhimento mais informações sobre o tema, para que produzam materiais que promovem o respeito e a boa convivência desses migrantes com a comunidade transgênero local. Por outro lado, espera-se também ter dado uma pequena contribuição para o acolhimento dos refugiados transgêneros, autodeclarados ou não, provendo-lhes as ferramentas linguísticas e culturais necessárias para que se integrem à 
comunidade transgênero local e sejam capazes de se comunicar de forma eficiente e satisfatória com seus pares e com outros membros da sociedade. Afinal, a integração linguística do refugiado, e até mesmo o pleno exercício de seus direitos humanos, passam também pela comunicação.

Por meio dessa pesquisa foi possível analisar os textos voltados às pessoas trans ou não e perceber a forma da qual este público tem sido tratado. Dessa forma, a linguagem é uma grande a forma para fazer essa identificação com o auxílio da Linguística de Corpus.

Por um lado é possível perceber, de acordo com a coleta de textos e, principalmente, do rank, que existe uma preferência, de forma geral, em referir-se a pessoas transgêneros com o termo "pessoas" a remeter a identidade de gênero do indivíduo. Foi constatado também o tratamento que tem-se dado às pessoas transgêneros e que tem sido respeitado minimamente, salvo os termos equivocados principalmente em matérias jornalísticas.

Além disso, foi interessante constatar que existem cada vez mais textos que versam especificamente sobre a temática da população trans não-binária ${ }^{12}$ que também precisa ser incluída mais incisivamente em questões da comunidade trans. No que se refere ao pronome adequado a este grupo é considerável pontuar que foi constatado uma relatividade de cada indivíduo.

Em contrapartida, foi constatado reincidências que indicam ser necessário uma discussão bastante específica sobre a linguagem adequada para o público dos refugiados em relação a como tratar pessoas LGBTQIA+ por parte quem produz os materiais instrutivos e específicos.

\section{REFERÊNCIAS}

ADELMAN, Miriam. Travestis e transexuais e os outros: identidade e experiências de vida. Niterói: UFF, 2003.

BALZER, Carsten; Jan Simon HUTTA. Transrespect versus transphobia worldwide: a comparative review of the human-rights situation of gender-variant/trans people. TvT Publication Series Vol. 6. Transgender Europe, 2012. Disponível em: http://transrespect.org/wp-content/uploads/2015/08/TvT_research-report.pdf. Acesso em: 05/4/2017.

BERBER SARDINHA, Tony. Lingüística de corpus. Barueri: Manole, 2004. 410p.

12 Termo guarda-chuva que embarca várias identidades diferentes dentro de si para identidades de gênero que não sejam exclusivamente homem nem mulher, estando, portanto fora do binário de gênero. 
CALVET, Louis-Jean. Sociolinguística: uma introdução crítica. Trad. Marcos Marcionilo. São Paulo: Parábola Editorial, 2002. 176p.

FERRARI, G. Geala. A despatologização do transtorno de identidade de gênero: uma crítica à patologização e o enaltecimento ao direito a identidade sexual dos indivíduos trans. In: SEMINÁRIO INTERNACIONAL DE DEMANDAS SOCIAIS E POLÍTICAS NA SOCIEDADE CONTEMPORÂNEA, 11.; MOSTRA DE TRABALHO JURÍDICO CIENTÍFICOS, 7., 2014, Santa Cruz do Sul. Anais [...]. Santa Cruz do Sul, 2014.

KULICK, Don. Travesti: prostituição, sexo, gênero e cultura no Brasil. Rio de Janeiro: Fiocruz, 2008.

OLIVEIRA, Gilvan Muller (Org.). Declaração universal dos direitos linguísticos. São Paulo: Mercado das Letras, Associação de Leitura do Brasil (ALB); Florianópolis: IPOL, 2003.

ORGANIZAÇÃO MUNDIAL DA SAÚDE. Classificação de transtornos mentais e de comportamento da CID-10: descrições clínicas e diretrizes diagnósticas. Porto Alegre: Artmed, 1993.

SAMPAIO, Liliana Lopes Pedral; COELHO, Maria Thereza Ávila Dantas. Quando o estranhamento se traduz em preconceito: trajetórias de vida de pessoas transexuais. In: VIEIRA, Tereza Rodrigues (Org.). Minorias Sexuais: direitos e preconceitos. Brasília: Consulex, 2012, p. 341-351.

SANTOS, Maria de Fátima Lima. A construção do dispositivo da transexualidade: saberes, tessituras e singularidades nas vivências trans. In: SEMINÁRIO INTERNACIONAL ENLAÇANDO SEXUALIDADES, 2011, Salvador. Anais [...]. Salvador, BA: Centro de Convenções da Bahia, 2011.

TEIXEIRA, E. D. A Linguística de Corpus a serviço do tradutor: proposta de um dicionário de Culinária voltado para a produção textual. 2008. 450 f. Tese (Doutorado em Estudos Linguísticos e Literários em Inglês) - Faculdade de Filosofia, Letras e Ciências Humanas, Universidade de São Paulo, São Paulo, 2008,.

VIEIRA, Tereza Rodrigues. Adequação de nome e sexo e a vulnerabilidade do transexual. In: VIEIRA, Tereza Rodrigues (Org.). Minorias Sexuais: direitos e preconceitos. Brasília: Consulex, 2012. p. 375-396. 


\section{Como referenciar este artigo}

SOUZA, João Roberto dos Reis de. Diversidade sexual e integração linguística: facilitando o contato inicial de migrantes com os transgêneros brasileiros. Rev. Sem Aspas, Araraquara, v.8, n.2, p. 167-179, jul./dez., 2019. e-ISSN: 2358-4238. DOI: https://doi.org/10.29373/sas.v8i2.13147

Submetido em: 22/11/2019

Revisões requeridas: 05/12/2019

Aprovado em: 08/12/2019

Publicado em: 30/12/2019 